\title{
Evaluating Experiential Avoidance in terms of COVID-19 Fear and Pandemic Emotional Distress Symptoms Among Latinx Adults
}

\author{
Nubia A. Mayorga ${ }^{1} \cdot$ Kara F. Manning $^{1} \cdot$ Jaye L. Derrick ${ }^{1} \cdot$ Andres G. Viana $^{1,2} \cdot$ Lorra Garey $^{1} \cdot$ Pamella Nizio $^{1}$. \\ Cameron T. Matoska ${ }^{1} \cdot$ Michael J. Zvolensky ${ }^{1,3,4}$ (1)
}

Accepted: 25 August 2021 / Published online: 1 September 2021

(C) The Author(s), under exclusive licence to Springer Science+Business Media, LLC, part of Springer Nature 2021

\begin{abstract}
Background The outbreak of the novel 2019 SARS2-Coronavirus disease (COVID-19) has led to substantial psychological distress across the United States and the world. However, emerging work suggests that prominent COVID-19 consequences such as fear of COVID-19 infection and emotional distress resulting from economic adversity and social distancing may afflict the Latinx population disproportionately. The current study sought to investigate the influence of experiential avoidance (EA), or an individual's tendency to rigidly avoid negative internal experiences (i.e. feelings, thoughts, etc.), on the severity of COVID-19 fear and emotional distress symptoms due to economic adversity and social distancing.

Method Participants included 188 Latinx persons recruited via an online survey panel program.

Results Results indicated that EA was a statistically significant contributing factor to fear of COVID-19 and emotional distress associated with economic adversity and social distancing. These effects were evident over and above the variance accounted for by gender, years living in the United States, education, and COVID-19 related work and home life stress.

Conclusions Overall, the present work is the first to document empirically EA as it relates to fear of COVID-19 infection and related emotional distress resulting from economic adversity and social distancing among Latinx persons.
\end{abstract}

Keywords Latinx $\cdot$ COVID-19 $\cdot$ Coronavirus $\cdot$ Pandemic $\cdot$ Fear $\cdot$ Emotional Distress

\section{Introduction}

The COVID-19 pandemic has contributed to an exponential rise in mental health symptoms and disorders in the United States (U.S.) and the world (Czeisler, 2020; Pfefferbaum \& North, 2020). Racial and ethnic minorities have been particularly affected by COVID-19 in terms of behavioral health problems (Double Jeopardy COVID-19 and Behavioral Health, 2020). For example, among Latinx persons, approximately $63 \%$ of individuals have reported elevated symptoms

Michael J. Zvolensky

mjzvolen@central.uh.edu

1 Department of Psychology, University of Houston, 3695 Cullen Blvd., Room 126, Houston, TX 77204, USA

2 Texas Institute of Measurement, Evaluation, and Statistics, Houston, USA

3 HEALTH Institute, University of Houston, Houston, TX, USA

4 Department of Behavioral Science, The University of Texas MD Anderson Cancer Center, Houston, TX, USA of emotional distress (McCormack, 2020). Other work suggests that older Latinx adults experience higher levels of COVID-19 related emotional distress symptoms than nonLatinx Black Americans and non-Latinx White Americans (Bui et al., 2021). Since the emergence of COVID-19, up to $35 \%$ of Latinx persons have endorsed symptoms that qualify as "serious mental distress" compared to $26 \%$ of non-Latinx White persons (as measured by the K9; Kessler et al., 2010; Twenge \& Joiner, 2020).

One of the most common psychological reactions to COVID-19 has been the fear of contracting the virus (Fitzpatrick et al., 2020). Fear of contracting COVID-19 has been related to an increased risk of mental health problems, including suicidal ideation (Dsouza et al., 2020). Further, independent of COVID-19 infection, fear of COVID-19 has been related to poorer mental and physical health (Colizzi et al., 2020; Liu et al., 2020; Stress in AmericaTM, 2020: Stress in the Time of COVID-19, Volume One, 2020). For example, COVID-19 fear has been associated with heightened inflammatory response and more severe psychiatric symptoms (Zarghami, 2020). Additionally, COVID-19 fear 
is related to worse daily life functioning (Lee et al., 2020). Most of the research on COVID-19 fear has been focused on the general population, and there is little information about how such fear manifests among health disparity groups such as Latinx persons. Some of the limited available work has found that certain sociodemographic factors, such as sex, have been linked to higher levels of COVID-19 fear among Latinx individuals (Rodríguez-Hidalgo et al., 2020). However, there is little understanding of which individual difference factors at a psychological level may be related to COVID-19 fear among Latinx persons.

The emotional impact of COVID-19 has also been evident in relation to economic and social distancing. In general, unemployment rates have increased during the COVID19 pandemic (14.5\%; Falk et al., 2021). Latinx persons have been disproportionately affected in terms of job loss $(18.9 \%$ Latinx Americans compared to $14.2 \%$ non-Latinx White Americans), and notably, these gaps have persisted through at least the end of the year 2020 (Falk et al., 2021). The emotional impact of COVID-19 financial stress has been related to increased overall stress and poorer mental health (Blanco et al., 2021). However, data on the emotional impact of COVID-19 economic stress among the Latinx community is highly limited. Similarly, the emotional impact of social distancing due to COVID-19 has also been recognized as an important factor influencing mental health. Although a protective measure against the spread of COVID-19, social distancing can be related to increased stress and isolation (Farboodi et al., 2020; Hoffart et al., 2020). Social distancing may be particularly distressing among Latinx persons, as family closeness is an important cultural value and protective factor for overall emotional well-being among this population (Bermudez \& Mancini, 2013; Rivera et al., 2008). Moreover, with elevated rates of infection among Latinx persons (Macias Gil et al., 2020), those who are separated from family members may experience heightened levels of emotional distress (Grief is "everywhere": Coronavirus takes mental health toll on Latino families., 2021). Therefore, there is a need to better understand which psychological processes may be related to increased negative emotional impact of COVID-19 due to economic and social distancing factors among the Latinx population.

One individual difference factor linked to psychological maladjustment in non-COVID-19 work among the Latinx population is experiential avoidance (EA). EA reflects the unwillingness to engage with internal experiences that are uncomfortable or painful, including emotions, thoughts, or physical sensations (Hayes et al., 1996). Individuals higher in EA exhibit a tendency to avoid or attempt to control negative internal experiences and the contexts that cause them (Kashdan et al., 2009; Ottenbreit \& Dobson, 2004). In nonCOVID-19 related work, EA has been related to negative mental health for the Latinx population (Raines et al., 2018;
Zvolensky et al., 2015). For example, among Latinx adults, EA has been linked to increased severity of anxiety symptoms (Zvolensky et al., 2016). However, no investigations have explored EA in relation to emotional or psychological maladjustment during/post COVID-19 among Latinx persons.

EA may be related to greater negative emotional impact of COVID-19 and emotional distress attributed to economic and social distancing protocols among the Latinx population. Specifically, the tendency to be cognitively inflexible (i.e. rigid), and unwilling to remain in contact with aversive internal experiences, including distressing thoughts, emotions, and physical sensations engendered by COVID-19 stressors, may be linked to deliberate and automatic efforts to alter the form, frequency, or contexts that cause these experiences. This rigid pattern of escape- and avoidance-oriented behavior may lead to greater COVID-19 psychological distress in the long term (e.g. substance use, emotional suppression; Levin et al., 2012). Moreover, such inflexible avoidance behavior, in turn, may make these COVID-19 stimuli more emotionally salient. EA may be especially relevant to Latinx persons, a population that has been linked to avoidance-oriented responses to mental health, such as stoicism (Cagle \& Bunting, 2017).

The present study sought to investigate whether EA was related to more severe fear of COVID-19 and the emotional impact of social distancing and economic stress among Latinx persons during COVID-19. It was hypothesized EA would be related to greater fear of COVID-19 and psychological distress resulting from such prominent and ongoing COVID-19 related consequences as social distancing and economic adversity. It was predicted EA would be related significantly to these criterion variables over and above the influence accounted for by years living in the U.S. (Alegría et al., 2007), COVID-19 impact (Zhou et al., 2020), gender identity (Van der Vegt \& Kleinberg, 2020), age (Seçer \& Ulaş, 2020), education (Roll et al., 2020), number of health conditions, work-life distress, and home-life distress among Latinx persons (Latinos \& COVID-19 Risks Are Tied to Everyday Life., 2020).

\section{Methods}

\section{Participants}

The present study included 188 Latinx persons (31.4\% female, $M_{\text {age }}=34.1$ years, $S D=8.16$ ). Participants were recruited via an online survey panel program (data collected from 5/2020 to 12/2020), Amazon Mechanical Turk (Mturk), due to the inability to conduct in-person research during the COVID-19 pandemic. Study eligibility criteria included being 18-65 years old, self-identifying as a Latinx 
person, currently living in the U.S., and being able to provide informed consent. Exclusion criteria included being younger than 18 years or older than 65 years, being a nonEnglish speaker (to ensure comprehension of the study questions), and inability to give informed and voluntary consent.

\section{Measures}

Demographics Questionnaire. Demographic information was gathered to characterize the sample and included age, gender, sexual orientation, primary language, ethnicity, education (recoded as $0=$ less than college degree and $1=$ Bachelor's degree or above), employment status, marital status, years in U.S., COVID-19 impact (i.e. "How much has/did COVID-19 impacted your day-to-day life?"), COVID-19 exposure (i.e. "What is the approximate size of the COVID19 outbreak in your area?"), as well as preexisting medical conditions. The COVID-19 impact question was scored on a 5 -item Likert type scale with the following options: $1=$ not at all, $2=$ a little, $3=$ much, $4=$ very much, $5=$ extremely.

The Epidemic-Pandemic Impacts Inventory (EPII; Grasso et al., 2020). The EPII is a 92-item self- report inventory of pandemic-related experiences that range across five separate life domains, including work life (12-items), home life (19items), social activities and isolation (18-items), emotional/ physical health and infection (24-items), and positive change (19-items). The current study included work life (e.g. "hard time making the transition to working from home") and home life (e.g. "increase in physical conflict with a partner or spouse") as covariates (work: $\alpha=0.88$, home: $\alpha=0.89$ ). For each subscale, all "yes" answers were given a value of 1 and all "no" answers were given a value of 0 . All "yes" values were summed and the higher the score, the increased level of distress in the respective domain.

Brief Experiential Avoidance Questionnaire (BEAQ; (Gámez et al., 2014). The BEAQ is a 15-item self-report measure that assesses experiential avoidance. All items are rated on a 6-point Likert scale ranging from 1 (strongly disagree) to 6 (strongly agree). The total score was used as a predictor variable, with higher scores denoting increased experiential avoidance levels. This measure demonstrated excellent internal consistency in the current sample $(\alpha=0.94)$, as well as in previous work (Gámez et al., 2014).

Fear of Coronavirus-19 Scale (FCV-19; Ahorsu et al., 2020). The FCV is a 7-item self-report scale that measures the severity of COVID-19 fears (e.g. "My heart races or palpitates when I think about getting coronavirus-19"). Participants are asked to rate their level of agreement with the statements provided from 1 (strongly disagree) to 5 (strongly agree). Total scores ranged from 7 to 35, with higher scores indicating greater fear of COVID-19. This measure has demonstrated a unidimensional structure in past work (Ahorsu et al., 2020) and was employed as a criterion variable $(\alpha=0.88)$.

Emotional Impact of Covid-19 (Schmidt et al., 2020). The Emotional Impact of COVID-19 (EIC) is a 12-item self-report questionnaire for assessing the impact of the COVID-19 pandemic on an individual's emotional functioning. The EIC has three subscales (COVID-19 outbreak, social distancing, and economic impact) with four items per subscale. Each subscale inquiries about the emotional impact of COVID-19 in terms of (1) COVID-19 outbreak (e.g. "Related to the COVID-19 outbreak, please rate your (loneliness, anger, fear, sadness) from 0 to 100"), (2) social distancing (e.g. "Related to the social distancing as a result of COVID-19, please rate your (loneliness, anger, fear, sadness) from 0 to 100"), and (3) economic impact (e.g. "Related to the economic impact as a result of COVID-19, please rate your (loneliness, anger, fear, sadness) from 0 to 100 "). A total score was used to determine the severity in distress across all subscales with higher scores indicating more severe distress. The EIC subscales of social distancing and economic impact were utilized as criterion variables and demonstrated excellent internal reliability ( $\alpha=0.93, \alpha=0.94)$.

\section{Procedure}

Participants were recruited from across the U.S. via Amazon Mechanical Turk (Mturk). Mturk is an online survey management system that has been found to yield valid and representative data (Kim \& Hodgins, 2017). According to eligibility criteria, participants were directed to the study participation link, and if interested, they completed the online survey. Prior to completing the survey, participants provided informed consent. The survey took approximately 60 min to complete, and participants were compensated with credit through their Mturk account. Each participant was compensated a total of $\$ 4.00$ for completing the survey. Mturk allows researchers to specify the quality criteria for their sample. In the current study, participants were shown the study information if they: (1) had never been blocked from a study, (2) performed at more than 90\% accuracy on other studies, and (3) passed a Human Intelligence Test (HIT), such as identifying pictures or filling in a CAPTCHA test. To further ensure data quality, IP addresses were obtained to prohibit duplicate responses. Additionally, less than $1 \%$ of responses were omitted based on missing information, incorrect responding to three out of four quality check questions, completion times less than $10 \mathrm{~min}$, or evidence of nonsensical responses. The study protocol was approved by the Institutional Review Board at the supporting institution. 


\section{Analytic Strategy}

Analyses were conducted using SPSS version 25. Sample descriptive statistics and zero-order correlations among study variables were examined. Three separate, two-step hierarchical regressions were conducted for each of the criterion variables: (1) fear of COVID-19; (2) emotional impact of social distancing due to COVID-19; and (3) emotional impact of economic adversity due to COVID-19. For all analyses, step 1 covariates included years living in the U.S.(Rumbaut, 2004), COVID-19 impact (McCormack, 2020), gender identity (Wassertheil-Smoller et al., 2014), age (Rumbaut, 2004), education (Morales et al., 2002), number of health conditions, work-life distress, and home-life distress (Taylor et al., 2020). Step 2 included experiential avoidance. Model fit for each of the steps was evaluated with the $F$ statistic and an increase in variance accounted for as evidenced by a change in $R^{2}$. Squared semi-partial correlations $\left(s r^{2}\right)$ were used as measures of effect size $(0.1$ small, 0.3 medium, 0.5 large; Dudgeon, 2016). A Bonferroni correction was employed; level of statistical significance was adjusted to 0.017 (i.e. $0.05 / 3$ ).

\section{Results}

\section{Descriptive Statistics}

Bivariate correlations and descriptive statistics are presented in Table 1 . The present sample consisted of predominately Latinx White/Caucasian (52.1\%) individuals, followed by
27.1\% Latinx Black/African Americans, 6.4\% identified as other, 5.9\% as more than one race, 3.7\% Latinx Asian individuals, $1.6 \%$ Latinx Native American/Alaska Native individuals, $1.6 \%$ as Latinx Native Hawaiian or Pacific Islander individuals, and $1.6 \%$ declined to state. Most participants (64.9\%) identified as heterosexual, $29.8 \%$ identified as bisexual, $3.2 \%$ identified as gay or lesbian, and $2.1 \%$ indicated they preferred not to disclose their sexuality. Regarding education, $13.8 \%$ of the participants indicated some college, $54.8 \%$ had a bachelor's degree, $30.3 \%$ had a master's degree, and $1.1 \%$ had a doctoral degree. More than half of the sample indicated they were married or living with someone $(82.4 \%)$.

In terms of pre-existing illnesses, $25.5 \%$ of persons indicated having an autoimmune disease, $42.02 \%$ respiratory disease, $8.5 \%$ HIV, $19.7 \%$ gastrointestinal issues, $16.0 \%$ cardiovascular disease, $33.0 \%$ diabetes, $12.8 \%$ kidney disease, and $35.1 \%$ reported having high blood pressure. Participants reported living in the U.S. an average of $31.02(S D=10.60)$ years, and $96 \%$ of the sample indicated that they were born in the U.S. In terms of unemployment, $32.6 \%$ of the sample reported being laid-off or let go from their employment since the onset of the COVID-19 pandemic.

\section{Regression Analyses}

Regression results are presented in Table 2. In terms of fear of COVID-19, step one of the model with covariates was statistically significant with COVID-19 impact, home distress, and number of health conditions emerging as statistically

Table 1 Bivariate correlations and descriptive statistics

\begin{tabular}{|c|c|c|c|c|c|c|c|c|c|c|c|c|c|}
\hline & 1 & 2 & 3 & 4 & 5 & 6 & 7 & 8 & 9 & 10 & 11 & Mean/ $n$ & $S D / \%$ \\
\hline 1.Age & - & & & & & & & & & & & 34.07 & 8.16 \\
\hline 2.Gender ( $\%$ female) & -.06 & - & & & & & & & & & & 59 & $31.4 \%$ \\
\hline 3. Years in U.S & $.66^{* * *}$ & -.06 & - & & & & & & & & & 31.10 & 10.60 \\
\hline 4.Education ( $\% \geq$ Bachelor's) & .08 & -.08 & .11 & - & & & & & & & & 162 & $86.2 \%$ \\
\hline 5.COVID Impact & $-.14^{*}$ & -.06 & -.05 & $.23^{* *}$ & - & & & & & & & 3.76 & 1.20 \\
\hline 6.EPII-work & .07 & .03 & .05 & $.41^{* * * *}$ & $.26^{* * *}$ & - & & & & & & 6.85 & 3.50 \\
\hline 7.EPII-home & .10 & .07 & .07 & $.39^{* * * *}$ & $.23^{* *}$ & $.90^{* * *}$ & - & & & & & 7.60 & 4.60 \\
\hline 8.Health conditions & $.26^{* * *}$ & .01 & $.15^{*}$ & $.16^{*}$ & -.04 & $.32^{* * *}$ & $.33^{* * *}$ & - & & & & 2.17 & 2.66 \\
\hline 9.Experiential avoidance & .06 & -.02 & .06 & $.24^{* *}$ & $.18^{*}$ & $.45^{* * *}$ & $.43^{* * *}$ & $.26^{* * *}$ & - & & & 10.72 & 4.90 \\
\hline 10.Fear of COVID & .08 & .01 & .07 & $.33^{* * *}$ & $.42^{* * *}$ & $.52^{* * *}$ & $.52^{* * *}$ & $.29^{* * *}$ & $.67^{* * *}$ & - & & 25.07 & 6.16 \\
\hline 11.Social distancing & .04 & -.09 & .06 & $.43^{* * * *}$ & $.35^{* * *}$ & $.46^{* * *}$ & $.45^{* * *}$ & $.25^{* *}$ & $.54^{* * * *}$ & $.65^{* * *}$ & & 236.20 & 105.36 \\
\hline 12.Income & .05 & -.12 & .06 & $.34^{* * * *}$ & $.38^{* * *}$ & $.42^{* * *}$ & $.39^{* * *}$ & $.21^{* *}$ & $.51^{* * *}$ & $.63^{* * *}$ & $.90^{* * *}$ & 237.71 & 107.44 \\
\hline
\end{tabular}

$N=188 ; * * * p<.001, * * p<.01, * p<.05$. Gender: $0=$ Male, $1=$ Female; Education: $0=$ less than Bachelor's Degree, $1=$ Bachelor's Degree or greater; COVID Impact: $1=$ not at all, $2=$ a little, $3=$ much, $4=$ very much, $5=$ extremely; EPII-Work The Epidemic-Pandemic Impacts Inventory-Work subscale (EPII; Grasso et al., 2020), EPII-Home The Epidemic-Pandemic Impacts Inventory-Home subscale (EPII; Grasso et al., 2020), Health Conditions Number of Health Conditions endorsed, Experiential Avoidance Brief Experiential Avoidance Questionnaire (BEAQ; Gámez et al., 2014), Fear of COVID Fear of Coronavirus-19 Scale (FCV; Ahorsu et al., 2020), Social Distancing Emotional Impact of Covid19-social distancing subscale (Schmidt, et al., 2020), Income Emotional Impact of Covid-19-impact to income subscale (Schmidt, et al., 2020) 
Table 2 Hierarchical regression results

\begin{tabular}{|c|c|c|c|c|c|c|c|c|}
\hline Model & & $\Delta R^{2}$ & $b$ & $S E$ & $\beta$ & $t$ & $p$ & $s r^{2}$ \\
\hline \multicolumn{9}{|c|}{ Fear of COVID } \\
\hline \multirow[t]{8}{*}{1} & Gender & $.43 * * *$ & 0.02 & 0.72 & .002 & 0.03 & .98 & .00 \\
\hline & Years in US & & -0.02 & 0.05 & -.03 & -0.37 & .71 & .001 \\
\hline & Age & & 0.06 & 0.06 & .08 & 0.96 & .34 & .003 \\
\hline & Education & & 0.61 & 1.17 & .04 & 0.52 & .60 & .001 \\
\hline & COVID-19 impact & & 1.93 & 0.33 & .38 & 5.93 & $<.001$ & .12 \\
\hline & EPII-work & & 0.12 & 0.24 & .07 & 0.51 & .61 & .001 \\
\hline & EPII-home & & 0.41 & 0.18 & .30 & 2.27 & .03 & .02 \\
\hline & Health conditions & & 0.37 & 0.15 & .16 & 2.48 & .01 & .02 \\
\hline 2 & Experiential avoidance & $.19 * * *$ & 0.24 & 0.03 & .49 & 8.85 & $<.001$ & .19 \\
\hline \multicolumn{9}{|c|}{ Social distancing } \\
\hline \multirow[t]{8}{*}{1} & Gender & $.35 * * *$ & -12.41 & 13.01 & -.06 & -0.95 & .34 & .004 \\
\hline & Years in US & & -0.21 & 0.87 & -.02 & -0.24 & .82 & .0002 \\
\hline & Age & & 0.09 & 1.14 & .01 & 0.08 & .94 & .000 \\
\hline & Education & & 71.19 & 21.15 & .24 & 3.37 & .001 & .04 \\
\hline & COVID-19 impact & & 20.77 & 5.88 & .24 & 3.53 & .001 & .05 \\
\hline & EPII-work & & 0.56 & 4.32 & .02 & 0.13 & .90 & .0001 \\
\hline & EPII-home & & 5.72 & 3.23 & .25 & 1.76 & .08 & .01 \\
\hline & Health conditions & & 5.08 & 2.72 & .13 & 1.86 & .06 & .01 \\
\hline 2 & Experiential avoidance & $.11 * * *$ & 3.10 & 0.55 & .37 & 5.60 & $<.001$ & .11 \\
\hline \multicolumn{9}{|l|}{ Income } \\
\hline \multirow[t]{8}{*}{1} & Gender & $.29 * * *$ & -21.01 & 13.76 & -.10 & -1.53 & .13 & .01 \\
\hline & Years in US & & -0.25 & 0.92 & -.02 & -0.27 & .79 & .0003 \\
\hline & Age & & 0.62 & 1.21 & .05 & 0.51 & .61 & .001 \\
\hline & Education & & 38.23 & 22.37 & .13 & 1.71 & .09 & .01 \\
\hline & COVID-19 impact & & 26.22 & 6.22 & .30 & 4.22 & $<.001$ & .08 \\
\hline & EPII-work & & 4.88 & 4.57 & .16 & 1.07 & .29 & .005 \\
\hline & EPII-home & & 2.10 & 3.44 & .09 & 0.61 & .54 & .002 \\
\hline & Health conditions & & 4.44 & 2.88 & .11 & 1.54 & .13 & .01 \\
\hline 2 & Experiential avoidance & $.10 * * *$ & 3.12 & 0.59 & .37 & 5.28 & $<.001$ & .10 \\
\hline
\end{tabular}

$\mathrm{N}=188$; *** $p<.001, * * p<.01, * p<.05$. Gender: $0=$ Male, $1=$ Female; Education: $0=$ less than Bachelor's Degree, $1=$ Bachelor's Degree or greater; COVID Impact: $1=$ not at all, $2=$ a little, $3=$ much, $4=$ very much, 5 = extremely; EPII-Work The Epidemic-Pandemic Impacts Inventory-Work subscale (EPII; Grasso et al., 2020), EPII-Home The Epidemic-Pandemic Impacts Inventory-Home subscale (EPII; Grasso et al., 2020), Health Conditions Number of Health Conditions endorsed, Experiential Avoidance Brief Experiential Avoidance Questionnaire (BEAQ; Gámez et al., 2014), Fear of COVID Fear of Coronavirus-19 Scale (FCV; Ahorsu et al., 2020), Social Distancing Emotional Impact of Covid-19-social distancing subscale (EIC; Schmidt, et al., 2020), Income Emotional Impact of Covid-19-impact to income subscale (EIC; Schmidt, et al., 2020)

significant predictors. In step two, experiential avoidance was a statistically significant predictor.

In terms of emotional impact of social distancing, step one was statistically significant with COVID-19 impact and education emerging as statistically significant predictors of the criterion variable. In step two, experiential avoidance was a statistically significant predictor.

In terms of emotional impact of COVID-19 economic adversity, step one of the model was statistically significant with COVID-19 impact emerging as a statistically significant predictor. In step two, experiential avoidance was a significant predictor.

\section{Discussion}

The current investigation examined EA in relation to the fear of COVID-19 and the emotional impact of social distancing and economic adversity among adult Latinx persons. Results were consistent with prediction. EA was related to increased fear of COVID-19 and emotional impact of social distancing and economic factors. The size of the observed effect for EA ranged from 10 to $19 \%$ of the variance, effects that were evident above and beyond the variance explained by general COVID-19 impact, gender 
identity, age, education, number of health conditions, work-life distress, and home-life distress.

Exploring the psychological predictors related to psychological adjustment during/post COVID-19 among Latinx persons is clinically relevant considering work that indicates COVID-19 health symptoms and distress over economic adversity and social distancing are expected to persist (Leviner, 2021; McKnight-Eily, 2021). Considering the size of EA effects across all models (i.e. 0.10-0.19), this construct appears to be an important individual difference psychological factor related to the COVID-19 emotional sequalae that has afflicted the Latinx population (McKnight-Eily, 2021). These results stand against the backdrop of non-Latinx person oriented COVID-19 work in which an individual's psychological flexibility facilitates COVID-19 psychological adjustment (Presti et al., 2020; Seçer et al., 2020). Future research is needed to isolate the mediational factors that may be involved in EA and emotional adjustment to COVID-19, including such processes that have been established across Latinx populations as emotion dysregulation (Mayorga et al., 2018), rumination (Paulus et al., 2018), and worry (McKnight-Eily, 2021; Rogers et al., 2020).

These results hold potential important clinical value. Behavioral health providers may benefit from screening for the experiences of Latinx individuals and family members in terms of fear of COVID-19 symptoms, economic adversity (e.g. unemployment), and degree of separation from family members during quarantine. Moreover, when identifying such factors, assessing elevated EA and targeting this construct via intervention programming may be a useful strategy to improve psychological adjustment related to COVID-19. EA is a mechanism malleable to intervention (Kashdan et al., 2014). Therefore, employing evidenced-based strategies such as Acceptance and Commitment Therapy (ACT; Hayes et al., 2011) to offset COVID-19 mental health concerns by reducing EA among Latinx adults may be an important strategy for those experiencing prolonged adjustment problems related to the pandemic. In fact, extant evidence suggests acceptance-based treatment strategies are potentially promising techniques for improving mental health among Latinx adults (Neff et al., 2003; Roth \& Robbins, 2004; Roth et al., 2018). This type of work may be most impactful when EA intervention programming is culturally adapted to the Latinx population, including such factors as engaging family cohesion, religious coping, speaking with loved ones about concerns with COVID-19, and future pandemic related fears (Rivera et al., 2008).

Although not primary study aims, several observations warrant comment. First, it is noteworthy the prevalence of pre-existing health illness among this sample was high, with respiratory disease endorsed by $42.02 \%$ of the sample. Further, such health conditions were related to greater COVID19 fear, possibly due to the highly publicized complicating features of health comorbidities on the clinical course of COVID-19 (Bendau et al., 2021). The high prevalence of co-occurring physical illnesses also highlights health disparities among Latinx adults (Macias Gil et al., 2020). Second, COVID-19 impact, as indexed by Emotional Impact of COVID-19 (Schmidt, et al., 2020), was related to each of the criterion variables. Not surprisingly, these data speak to the multidimensional nature of COVID-19 and the broadreaching impact of the pandemic across life domains among an adult Latinx sample.

Results should be interpreted considering the following limitations. First, the current sample was recruited from an online sample set due to the social distancing guidelines in place at the time of data collection. This cohort of Latinx individuals may have a higher level of comfort with and access to technology and a higher than average level of education compared to the general Latinx population (average educational level at 11\%; Schak et al., 2016). Although the generalizability of these results should be interpreted with caution, it is likely Latinx persons with lower access to technology and lesser levels of education may experience higher levels of emotional distress as they may endure greater economic disadvantage. Future work stands to benefit from investigating the current results across Latinx subpopulations, including those with lower levels of education. Second, the study implemented self-report measures, and therefore, method variance could influence the observed results. Multimethod assessments of key constructs are potentially useful to replicate and extend the findings in future research. Third, the data were collected at one time point. Consequently, the directionality and causality between the studied variables cannot be explicated. Future work could usefully examine the role of EA in COVID-19 emotional sequalae using time sampling approaches or other longitudinal designs. Lastly, $32.6 \%$ of the sample indicated having lost their employment since COVID-19. Future research may benefit by evaluating emotional distress levels among samples with higher and lower levels of economic impact from COVID-19.

Overall, the present work is the first to empirically document the influence of EA in terms of fear of COVID-19 levels and the COVID-19 emotional distress that results from economic adversity and social distancing among Latinx persons. These criterion variables are prevalent and impactful COVID-19 consequences and are expected to continue post-COVID-19. Future longitudinal research would be a useful next research step to better understand the role of EA in COVID-19 mental health disparities among adult Latinx persons.

Funding Research reported in this publication was supported by the National Institute on Minority Health and Health Disparities (NIMHD) 
of the National Institutes of Health (NIH) to the University of Houston under Award Number U54MD015946. The content is solely the responsibility of the authors and does not necessarily represent the official views of the National Institutes of Health.

\section{Declarations}

Conflict of Interest Nubia A. Mayorga, Kara F. Manning, Jaye L. Derrick, Andres G.Viana, Lorra Garey, Pamella Nizio, Cameron T. Matoska, \& Michael J. Zvolensky declare that they have no conflict of interest.

Informed Consent All procedures followed were in accordance with the ethical standards of the responsible committee on human experimentation (national and institutional). Informed consent was obtained from all individual subjects participating in the study. If any identifying information is contained in the paper the following statement is also necessary -- Additional informed consent was obtained from any subjects for whom identifying information appears in this paper.

Animal Rights No animal studies were carried out by the authors for this article.

\section{References}

Ahorsu, D. K., Lin, C.-Y., Imani, V., Saffari, M., Griffiths, M. D., \& Pakpour, A. H. (2020). The fear of COVID-19 scale: development and initial validation. International Journal of Mental Health and Addiction. https://doi.org/10.1007/s11469-020-00270-8

Alegría, M., Mulvaney-Day, N., Torres, M., Polo, A., Cao, Z., \& Canino, G. (2007). Prevalence of psychiatric disorders across latino subgroups in the United States. American Journal of Public Health, 97(1), 68-75. https://doi.org/10.2105/AJPH.2006.087205

Bendau, A., Petzold, M. B., Pyrkosch, L., Maricic, L. M., Betzler, F., Rogoll, J., Große, J., Ströhle, A., \& Plag, J. (2021). Associations between COVID-19 related media consumption and symptoms of anxiety, depression and COVID-19 related fear in the general population in Germany. European Archives of Psychiatry and Clinical Neuroscience, 271(2), 283-291.

Bermudez, J. M., \& Mancini, J. A. (2013). Familias fuertes: Family resilience among Latinos. In D. S. Becvar (Ed.), Handbook of family resilience (pp. 215-227). NY: Springer.

Blanco, L., Cruz, V., Frederick, D., \& Herrera, S. (2021). Financial stress among Latino Adults in California during COVID-19. Journal of Economics, Race, and Policy,. https://doi.org/10.1007/ s41996-021-00087-0

Bui, C. N., Peng, C., Mutchler, J. E., \& Burr, J. A. (2021). Race and ethnic group disparities in emotional distress among older adults during the COVID-19 pandemic. The Gerontologist, 61(2), 262-272.

Cagle, J., \& Bunting, M. (2017). Patient reluctance to discuss pain: Understanding stoicism, stigma, and other contributing factors. Journal of Social Work in End-of-Life \& Palliative Care, 13(1), 27-43.

Colizzi, M., Bortoletto, R., Silvestri, M., Mondini, F., Puttini, E., Cainelli, C., Gaudino, R., Ruggeri, M., \& Zoccante, L. (2020). Medically unexplained symptoms in the times of Covid-19 pandemic: A case-report. Brain, Behavior, \& Immunity-Health, 5, 100073.

Czeisler, M. É. (2020). Mental Health, Substance Use, and Suicidal Ideation During the COVID-19 Pandemic — United States,
June 24-30, 2020. MMWR. Morbidity and Mortality Weekly Report, 69. https://doi.org/10.15585/mmwr.mm6932a1

Dsouza, D. D., Quadros, S., Hyderabadwala, Z. J., \& Mamun, M. A. (2020). Aggregated COVID-19 suicide incidences in India: Fear of COVID-19 infection is the prominent causative factor. Psychiatry Research, 290, 113145.

Dudgeon, P. (2016). A comparative investigation of confidence intervals for independentvariables in linear regression. Multivariate Behavioral Research, 51(2-3), 139-153.

Falk, G., Carter, J. A., Nicchitta, I. A., Nyhof, E. C., \& Romero, P. D. (n.d.). Unemployment Rates During the COVID-19 Pandemic: In Brief. 16.

Farboodi, M., Jarosch, G., \& Shimer, R. (2020). Internal and external effects of social distancing in a pandemic. National Bureau of Economic Research.

Fitzpatrick, K. M., Harris, C., \& Drawve, G. (2020). Fear of COVID19 and the mental health consequences in America. Psychological Trauma: Theory, Research, Practice, and Policy.

Gámez, W., Chmielewski, M., Kotov, R., Ruggero, C., Suzuki, N., \& Watson, D. (2014). The brief experiential avoidance questionnaire: Development and initial validation. Psychological Assessment, 26(1), 35.

Grasso, D. J., Briggs-Gowan, M. J., Carter, A. S., Goldstein, B., \& Ford, J. D. (2020). A Person-Centered Approach to Profiling COVID-Related Experiences in the United States: Preliminary Findings from the Epidemic-Pandemic Impacts Inventory (EPII).

Grief is "everywhere": Coronavirus takes mental health toll on Latino families. (n.d.). NBC News. Retrieved March 25, 2021, from https://www.nbcnews.com/news/latino/hard-hit-covid-19-latin os-bear-mental-health-burden-8-n1248199.

Hayes, S. C., Strosahl, K. D., \& Wilson, K. G. (2011). Acceptance and commitment therapy: The process and practice of mindful change. Guilford Press.

Hayes, S. C., Wilson, K. G., Gifford, E. V., Follette, V. M., \& Strosahl, K. (1996). Experiential avoidance and behavioral disorders: A functional dimensional approach to diagnosis and treatment. Journal of Consulting and Clinical Psychology, 64(6), 1152.

Hoffart, A., Johnson, S. U., \& Ebrahimi, O. V. (2020). Loneliness and social distancing during the COVID-19 pandemic: Risk factors and associations with psychopathology. Frontiers in Psychiatry, 11, 1297.

Double Jeopardy COVID-19 and Behavioral Health Di.pdf. (n.d.). Retrieved November 11, 2020, from https://www.samhsa.gov/ sites/default/files/covid19-behavioral-health-disparities-blacklatino-communities.pdf.

Kashdan, T. B., Goodman, F. R., Machell, K. A., Kleiman, E. M., Monfort, S. S., Ciarrochi, J., \& Nezlek, J. B. (2014). A contextual approach to experiential avoidance and social anxiety: Evidence from an experimental interaction and daily interactions of people with social anxiety disorder. Emotion, 14(4), 769.

Kashdan, T. B., Morina, N., \& Priebe, S. (2009). Post-traumatic stress disorder, social anxiety disorder, and depression in survivors of the Kosovo War: Experiential avoidance as a contributor to distress and quality of life. Journal of Anxiety Disorders, 23(2), 185-196.

Kessler, R. C., Green, J. G., Gruber, M. J., Sampson, N. A., Bromet, E., Cuitan, M., Furukawa, T. A., Gureje, O., Hinkov, H., \& Hu, C.-Y. (2010). Screening for serious mental illness in the general population with the K6 screening scale: Results from the WHO World Mental Health (WMH) survey initiative. International Journal of Methods in Psychiatric Research, 19(S1), 4-22.

Kim, H. S., \& Hodgins, D. C. (2017). Reliability and validity of data obtained from alcohol, cannabis, and gambling populations on Amazon's Mechanical Turk. Psychology of Addictive Behaviors, $31(1), 85$. 
For Latinos, COVID-19 Risks Are Tied to Everyday Life. (n.d.). US News \& World Report. Retrieved November 11, 2020, from https://www.usnews.com/news/healthiest-communities/articles/ 2020-07-24/coronavirus-risks-tied-to-everyday-life-for-latinos.

Lee, S. A., Jobe, M. C., \& Mathis, A. A. (2020). Mental health characteristics associated with dysfunctional coronavirus anxiety. Psychological Medicine, 1-2.

Levin, M. E., Lillis, J., Seeley, J., Hayes, S. C., Pistorello, J., \& Biglan, A. (2012). Exploring the relationship between experiential avoidance, alcohol use disorders, and alcohol-related problems among first-year college students. Journal of American College Health, 60(6), 443-448.

Leviner, S. (2021). Recognizing the clinical sequelae of COVID19 in adults: COVID-19 Long-Haulers. The Journal for Nurse Practitioners. https://doi.org/10.1016/j.nurpra.2021.05.003

Liu, C. H., Zhang, E., Wong, G. T. F., \& Hyun, S. (2020). Factors associated with depression, anxiety, and PTSD symptomatology during the COVID-19 pandemic: Clinical implications for US young adult mental health. Psychiatry Research, 290, 113172.

Macias Gil, R., Marcelin, J. R., Zuniga-Blanco, B., Marquez, C., Mathew, T., \& Piggott, D. A. (2020). COVID-19 pandemic: Disparate health impact on the Hispanic/Latinx population in the United States. The Journal of Infectious Diseases, 222(10), $1592-1595$.

Mayorga, N. A., Jardin, C., Bakhshaie, J., Garey, L., Viana, A. G., Cardoso, J. B., \& Zvolensky, M. (2018). Acculturative stress, emotion regulation, and affective symptomology among Latino/a college students. Journal of Counseling Psychology, 65(2), 247.

McCormack, J. (2020, June 11). Mental Health, COVID-19, and Their Impacts on Latinos. Salud America. https://salud-america.org/ mental-health-covid-19-and-their-impacts-on-latinos/.

McKnight-Eily, L. R. (2021). Racial and Ethnic Disparities in the Prevalence of Stress and Worry, Mental Health Conditions, and Increased Substance Use Among Adults During the COVID-19 Pandemic - United States, April and May 2020. MMWR. Morbidity and Mortality Weekly Report, https://doi.org/10.15585/ mmwr.mm7005a3

Morales, L. S., Lara, M., Kington, R. S., Valdez, R. O., \& Escarce, J. J. (2002). Socioeconomic, cultural, and behavioral factors affecting Hispanic health outcomes. Journal of Health Care for the Poor and Underserved, 13(4), 477.

Neff, J. A., Amodei, N., Valescu, S., \& Pomeroy, E. C. (2003). Psychological adaptation and distress among HIV+ Latina women: Adaptation to HIV in a Mexican American cultural context. Social Work in Health Care, 37(3), 55-74.

Ottenbreit, N. D., \& Dobson, K. S. (2004). Avoidance and depression: The construction of the Cognitive-Behavioral Avoidance Scale. Behaviour Research and Therapy, 42(3), 293-313.

Paulus, D. J., Ditre, J. W., Viana, A. G., Bakhshaie, J., Garza, M., Valdivieso, J., Ochoa-Perez, M., Lemaire, C., \& Zvolensky, M. J. (2018). Pain and alcohol use among latinos in primary care: Examining rumination as an explanatory factor. Substance Use \& Misuse, 53(4), 686-693.

Pfefferbaum, B., \& North, C. S. (2020). Mental health and the Covid-19 pandemic. New England Journal of Medicine., 383(6), 510-512.

Presti, G., Mchugh, L., Gloster, A., Karekla, M., \& Hayes, S. C. (2020). The dynamics of fear at the time of covid-19: a contextual behavioral science perspective. Clinical Neuropsychiatry, 17(2), 65-71.

Raines, E. M., Rogers, A. H., Bakhshaie, J., Viana, A. G., Lemaire, C., Garza, M., Mayorga, N. A., Ochoa-Perez, M., \& Zvolensky, M. J. (2018). Mindful attention moderating the effect of experiential avoidance in terms of mental health among Latinos in a federally qualified health center. Psychiatry Research, 270, 574-580.

Rivera, F. I., Guarnaccia, P. J., Mulvaney-Day, N., Lin, J. Y., Torres, M., \& Alegria, M. (2008). Family cohesion and its relationship to psychological distress among Latino groups. Hispanic Journal of Behavioral Sciences, 30(3), 357-378.

Rodríguez-Hidalgo, A. J., Pantaleón, Y., Dios, I., \& Falla, D. (2020). Fear of COVID-19, stress, and anxiety in university undergraduate students: A predictive model for depression. Frontiers in Psychology, 11, 3041.

Rogers, A. H., Bogiaizian, D., Salazar, P. L., Solari, A., Garey, L., Fogle, B. M., \& Zvolensky, M. J. (in press). COVID-19 and anxiety sensitivity across two studies in Argentina: Associations with COVID-19 worry, symptom severity, anxiety, and functional impairment.

Roll, C. G., Yung Chun, Michal Grinstein-Weiss, and Stephen. (2020, June 24). Well-being and mental health amid COVID-19: Differences in resilience across minorities and whites. Brookings. https://www.brookings.edu/research/well-being-and-mentalhealth-amid-covid-19-differences-in-resilience-across-minor ities-and-whites/.

Roth, B. J., Crea, T. M., Jani, J., Underwood, D., Hasson, R. G., III., Evans, K., \& Hornung, E. (2018). Detached and afraid: US immigration policy and the practice of forcibly separating parents and young children at the border. Child Welfare, 96(5), 29.

Roth, B., \& Robbins, D. (2004). Mindfulness-based stress reduction and health-related quality of life: Findings from a bilingual innercity patient population. Psychosomatic Medicine, 66(1), 113-123.

Rumbaut, R. G. (2004). Ages, life stages, and generational cohorts: Decomposing the immigrant first and second generations in the United States 1. International Migration Review, 38(3), $1160-1205$.

Schak, J. O., \& Nichols, A. H. (n.d.). Degree Attainment for Latino Adults: National and State Trends. 11.

Schmidt, N. B., Allan, N. P., Koscinski, B., Mathes, B. M., Eakles, K., Accorso, C., Saulnier, K. G., Allan, D. M., Potter, K., Garey, L., Suhr, J., Austin, M., \& Zvolensky, M. J. (in press). COVID-19 Impact Battery: Development and validation. Journal of Psychopathology and Behavioral Assessment.

Seçer, I., \& Ulaş, S. (2020). An investigation of the effect of COVID-19 on OCD in youth in the context of emotional reactivity, experiential avoidance, depression and anxiety. International Journal of Mental Health and Addiction, 1-14.

Seçer, İ, Ulaş, S., \& Karaman-Özlü, Z. (2020). The effect of the fear of COVID-19 on healthcare professionals' psychological adjustment skills: Mediating role of experiential avoidance and psychological resilience. Frontiers in Psychology. https://doi.org/10.3389/ fpsyg.2020.561536

Stress in America ${ }^{T M}$ 2020: Stress in the Time of COVID-19, Volume One. (n.d.). Retrieved November 11, 2020, from https://www.apa. org/news/press/releases/stress/2020/report.

Taylor, S., Landry, C. A., Paluszek, M. M., Fergus, T. A., McKay, D., \& Asmundson, G. J. (2020). COVID stress syndrome: Concept, structure, and correlates. Depression and Anxiety, 37(8), 706-714.

Twenge, J. M., \& Joiner, T. E. (2020). Mental distress among US adults during the COVID-19 pandemic. Journal of Clinical Psychology, 76(12), 2170-2182.

Van der Vegt, I., \& Kleinberg, B. (2020). Women worry about family, men about the economy: Gender differences in emotional responses to COVID-19. International Conference on Social Informatics, 397-409.

Wassertheil-Smoller, S., Arredondo, E. M., Cai, J., Castaneda, S. F., Choca, J. P., Gallo, L. C., Jung, M., LaVange, L. M., Lee-Rey, E. T., \& Mosley, T., Jr. (2014). Depression, anxiety, antidepressant use, and cardiovascular disease among Hispanic men and women of different national backgrounds: Results from the Hispanic Community Health Study/Study of Latinos. Annals of Epidemiology, 24(11), 822-830.

Zarghami, M. (2020). Psychiatric aspects of coronavirus (2019-nCoV) infection. Iran J Psychiatry Behav Sci, 14(1), e102957. 
Zhou, Y., MacGeorge, E. L., \& Myrick, J. G. (2020). Mental health and its predictors during the early months of the COVID-19 pandemic experience in the United States. International Journal of Environmental Research and Public Health, 17(17), 6315.

Zvolensky, M. J., Bakhshaie, J., Garza, M., Valdivieso, J., Ortiz, M., Bogiaizian, D., Robles, Z., Schmidt, N. B., \& Vujanovic, A. (2015). The role of anxiety sensitivity in the relation between experiential avoidance and anxious arousal, depressive, and suicidal symptoms among Latinos in primary care. Cognitive Therapy and Research, 39(5), 688-696.
Zvolensky, M. J., Jardin, C., Garey, L., Robles, Z., \& Sharp, C. (2016). Acculturative stress and experiential avoidance: Relations to depression, suicide, and anxiety symptoms among minority college students. Cognitive Behaviour Therapy, 45(6), 501-517.

Publisher's Note Springer Nature remains neutral with regard to jurisdictional claims in published maps and institutional affiliations. 